\title{
On the specific heats and melting-points of divers refractory metals
}

\section{J. Violle}

To cite this article: J. Violle (1879) On the specific heats and melting-points of divers refractory metals, Philosophical Magazine Series 5, 8:51, 501-502, DOI: $10.1080 / 14786447908639717$

To link to this article: http://dx.doi.org/10.1080/14786447908639717

曲 Published online: 13 May 2009.

Submit your article to this journal $\widetilde{ }$

Џ Article views: 2

Q View related articles $\sqsubset$ 


\section{$\left[\begin{array}{ll}501 & 0\end{array}\right.$}

\section{Intelligence and Miscellaneous Articles.}

ON THE SPECIFIC HEATS AND MELTING-POIN'S OF DIVERS

REFRACTORY METALS. BY J. VIOLLE.

I. THE specific heat of iridium, like that of platinum, increases

regularly with the temperature. The experiments were extended up to $1400^{\circ}$; and they are well represented by the formula found for platinum,

$$
\mathrm{C}_{0}=0 \cdot 0317+0 \cdot 000006 t
$$

From this the following values are deduced for the mean specific heat between zero and $t$ degrees:-

$\begin{array}{lll}\mathrm{C}_{0}^{100} & \ldots \ldots & 0.0323 \\ \mathrm{C}_{0}^{200} & \ldots \ldots & 0.0329 \\ \mathrm{C}_{0}^{300} & \ldots \ldots & 0.0335 \\ \mathrm{C}_{0}^{400} & \ldots \ldots & 0.0341 \\ \mathrm{C}_{0}^{500} & \ldots \ldots & 0.0347 \\ \mathrm{C}_{0}^{600} & \ldots \ldots & 0.0353 \\ \mathrm{C}_{0}^{700} & \ldots \ldots & 0.0359\end{array}$

$$
\begin{array}{lll}
\mathrm{C}_{0}^{800} & \ldots \ldots & 0.0365 \\
\mathrm{C}_{0}^{900} & \ldots \ldots & 0.0371 \\
\mathrm{C}_{0}^{1000} & \ldots \ldots & 0.0377 \\
\mathrm{C}_{0}^{1100} & \ldots \ldots & 0.0383 \\
\mathrm{C}_{0}^{1200} & \ldots \ldots & 0.0389 \\
C_{0}^{1300} & \ldots \ldots & 0.0395 \\
C_{0}^{1400} & \ldots \ldots & 0.0401
\end{array}
$$

It was not without some little difficulty that the melting-point of iridium could be determined; that metal in fact necessitates the employment of hydrogen and oxygen pure and dry in the blowpipe of Deville and Debray ; and to melt 20 grams of iridium not less than 500 litres of hydrogen and 250 litres of oxygen must be consumed. Nevertheless three experiments were brought to a successful issue, conducted in the manner indicated for platinum, and in which $24,8 \cdot 970$, and 8.404 grams of solid iridium gave up to the calorimeter, at the temperature of the fusion, respectively $84 \cdot 2$, 85.3 , and 83.9 units of heat per gram of metal, or a mean of 84.5 units. If, then, it be admitted that the formula above given represents the specific heat of iridium up to its melting-point, a temperature certainly very little below that of the blowpipe-flame, it follows that iridium fuses at $1950^{\circ} \mathrm{C}$.

II. Gold presents a mean specific heat which up to $600^{\circ}$ hardly varies at all, then sensibly increases in proportion as the meltingpoint is approached : equal to $0.0324 *$ (according to Regnault) between $0^{\circ}$ and $100^{\circ}$, still nearly the same at $600^{\circ}$, it reaches 0.0345 at $900^{\circ}$ and 0.0352 at $1020^{\circ}$. The melting-point of gold, determined as usual, is $1035^{\circ}$.

III. The melting-point of copper is very close to that of gold, but a little higher $\uparrow$ : pure copper melts at $1054^{\circ}$.

IV. Collecting in a Table the melting-points given in this and

* Gold of $\frac{999}{1000}$. I found a specific heat a little less, $C_{0}^{100}=0.0316$, with a specimen of perfectly pure gold which I used in my researches, and for which also I am indebted to the kindness of M. Debray.

+ The red copper of commerce melts before virgin gold, $15^{\circ}$ to $30^{\circ}$ before gold like the specimen. 
previous Notes, we have the following numbers, all referring to the air-thermometer :-

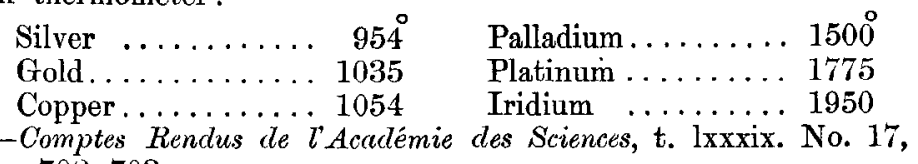
pp. 702,703 .

RESEARCHES ON DALTONISM. NOTE BY J. MACÉ AND W. NICATI.

I. Thanks to the kindness of the Principals of the Lyceums of Marseilles and Grenoble, and of the Principal of the Callege of Aix in Provence, we have been able to examine a total of 925 bovs, of whom 33 were daltonians, or 3.57 per cent. We have examined a smaller number of girls, or 241 , of whom one only was daltonian. For these elementary researches we have emploved Seebeck's method so ingeniously improved by M. Holmgren, consisting in getting the examinees to select, from a mass of specimens of coloured wool, those which are like some suitably chosen types, without troubling about the names, more or less accurate, that may be given to the colours. These researches have extended to too small a number of individuals to possess any real statistical value; nor was that our aim. They are nevertheless to a certain degree interesting from their agreement with the results obtained by Holmgren, Jeffries, and others abroad. On the other hand, they are utterly different from the results obtained by Dr. Favre, who finds from 20 to 30 daltonians per hundred individuals examined.

II. The principal object of our investigations has been to obtain comparative measures between the quantities of light perceived in the different parts of the spectrum by the daltonian and by the normal eye. In the experiments which we relate today we employed an indirect method. It is based upon the fact that the acuteness of vision diminishes simultaneously with the intensity of the light; and it consists in measuring the visual acuteness of the daltonian in the different portions of the spectrum, always comparing it with the visual acuteness, in the same circumstances, of a normal sight. Wo make use of a spectrum with a total length of more than 5 decimetres, thrown upon a stretched graduated rule of black velvet. Over this rule slides at will a square of white cardboard, from which a letter of the alphabet is cut out 5 millims. in diameter. (Letters written with ordinary ink fluoresce very inconveniently in the violet.) The measuring consists in ascertaining the maximum distance $d$ at which the daltonian must place himself in order to distinguish the character, and inmediately afterwards the corresponding distance $\mathrm{D}$ for one of us, always the same individual.

Determining in this way the values of the ratio $\frac{d}{\mathrm{D}}$ for the various regions of the spectrnm, we have obtained curves which may be referred to three types: one set, three in number, descend towards the red end of the spectrum; another curve descends towards the 